Alma Mater Studiorum - Università di Bologna DEPARTMENT OF ECONOMICS

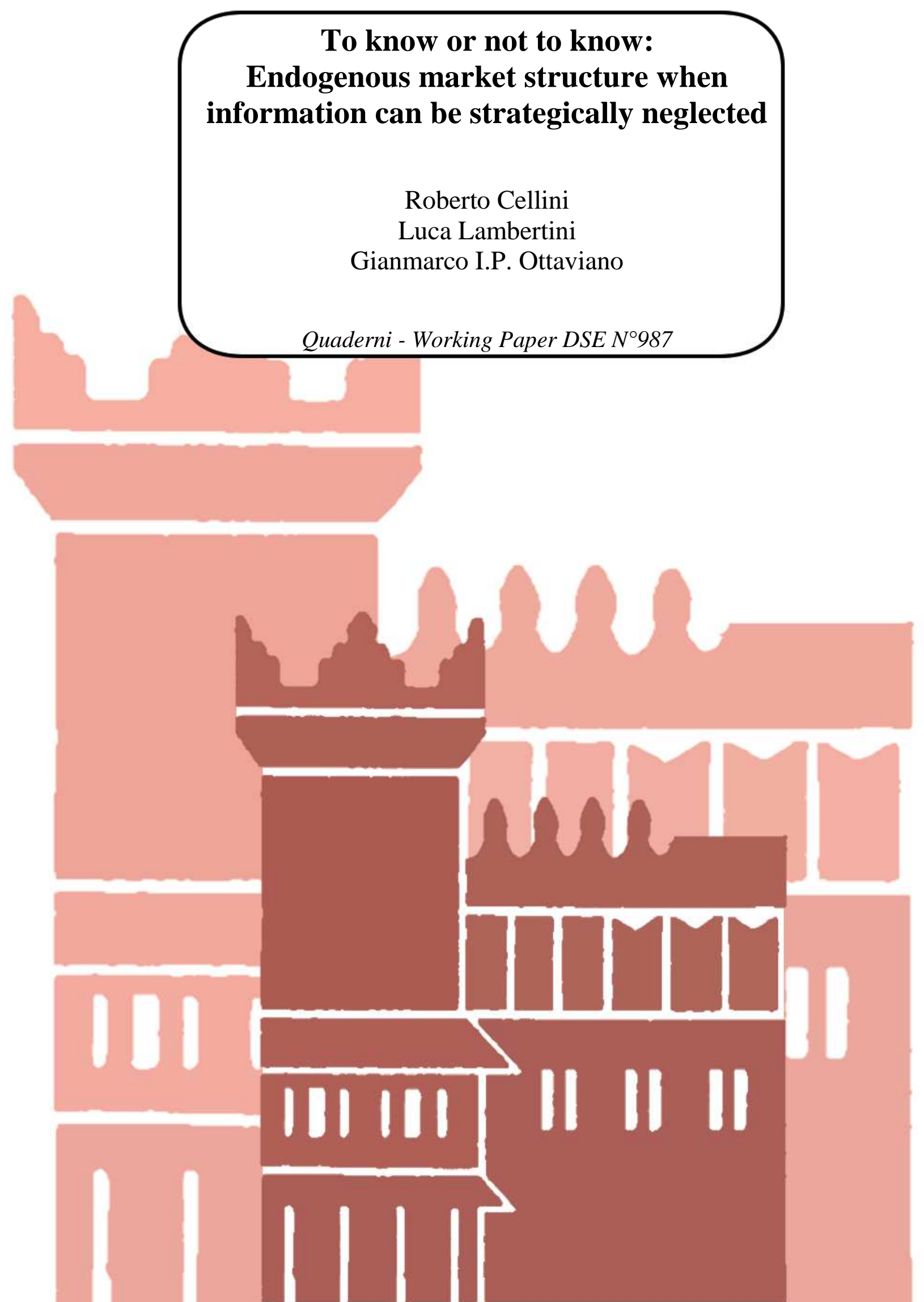




\title{
To know or not to know: Endogenous market structure when information can be strategically neglected*
}

\author{
Roberto Cellini ${ }^{(a)}$, Luca Lambertini ${ }^{(b)}$, Gianmarco I.P. Ottaviano ${ }^{(b, c)}$ \\ ${ }^{(a)}$ Università di Catania, cellini@unict.it \\ ${ }^{(b)}$ Università di Bologna, luca.lambertini@unibo.it, gianmarco.ottaviano@unibo.it \\ ${ }^{(c)}$ London School of Economics, g.i.ottaviano@lse.ac.uk
}

January 7, 2015

\begin{abstract}
We study the firms' choice of whether or not to consider pieces of information concerning their interdependence. In particular, any firm can strategically choose to consider or not the fact that industry output is affected by its own production choice. If this piece of information is considered, the firm behaves as an aligopolist; if not, firm behaves in a monopolistically competitive way. Thus, the market regime is endogenously determined. We show that different outcomes can emerge, depending on the number of firms, the degree of product substitutability and the cost structure.

Keywords: information; strategic interaction; monopolistic competition; oligopoly; delegation.

JEL Codes: D43, L13.

${ }^{*}$ We would like to thank Herbert Dawid, Juan Prieto Rodriguez, Jacques Francois Thisse and the seminar audience at the University of Bielefeld for useful comments and suggestions on a previous draft. The usual disclaimer applies.
\end{abstract}




\section{Introduction}

From a theoretical point of view, the distinction between oligopoly and monopolistic competition is clear: oligopoly models assume that firms are aware of their role in determining industry output and hence the market equilibrium, while monopolistic competition models assume that firms disregard this piece of information. In other words, monopolistically competitive firms take as given aggregate output when setting their individual production levels, while oligopolistic firms explicitly consider the effect that each individual choice exerts on the total market supply. Basically, the difference rests on the role of information concerning the effects of individual choices on aggregate market allocation. According to textbook economic analysis, markets can be either oligopolistic or monopolistically competitive, and the specific nature of a market regime is an exogenous assumption. In this paper we study the perspective in which firms can strategically choose whether or not to consider the effect of their individual decisions on market configuration, so that the determination of the market regime is endogenously driven by firms' strategic choices. ${ }^{1}$

Different outcomes can emerge, depending on the number of firms, and other parameters including the degree of product substitutability. In particular, the present paper shows that three alternative situations are possible: (1) only one equilibrium can exist, in which all firms behave as oligopolistic subjects; this equilibrium is Pareto-efficient for firms; (2) only one equilibrium exists, in which all firms behave as monopolistically competitive units: such an equilibrium is Pareto-inefficient for firms as compared to the outcome in which all firms are oligopolistic, but the full oligopolistic setting can not be an equilibrium; (3) two equilibria exist, namely, one in which all firms behave as oligopolistic agents, and the other where all firms behave as monopolistically competitive units, the former being Pareto-efficient for firms. In any case, the coexistence of heterogeneous behaviour on the part of firms in a given market can not be an equilibrium in pure strategies, since a unilateral profit incentive for at least one firm to adopt the alternative behaviour is al-

\footnotetext{
${ }^{1}$ Note that the label "endogenous market structure" in this article has a different meaning as compared to other studies, in which the firm choices concern aspects which are not taken into account in our present study; for instance, the entry or exit decision of individual producers (see, e.g., Etro 2008, 2011, 2012; Dunne et al. 2013): in our present model the number of operative firms is given, and the endegeneity of market structure is linked to the firm choices on whether or not to use available information.
} 
ways present. It is important to underline that we use the concept of Pareto efficiency or inefficiency, throughout the entire paper, with reference to the firms' standpoint only; no considerations are developed as far as consumer surplus and welfare are concerned.

Our model can be read as contribution to the study of the value of information. We assume that the information concerning the behaviour of all firms is freely accessible. In some circumstances, it could be individually convenient for a firm to ignore such a piece of information, even if its acquisition is costless. This means that the value of a piece of information can be negative for a firm, and the firm could find it optimal to constrain itself to ignore such a piece of (freely available) information. There is a comparatively small literature discussing the value of information in games, where players rationally prefer to ignore some potentially relevant pieces of information (Kamien, Tauman and Zamir, 1990; Bassan, Scarsini and Zamir, 1997; Bassan, Gossner, Scarsini and Zamir, 2003). From this strand of literature, there clearly emerges that information is not relevant per se, but rather for the way in which it affects players' best replies to rivals. ${ }^{2}$ Another specific case in which oligopolistic firms may find it convenient to omit to consider available pieces of information is presented by Barros (1997). In her model, by ignoring the information on the actions taken by their (sale) agents, oligopolistic principals forgo the possibility of appropriating the agents' benefits from their relation specific investments, which ends up increasing the principals' expected profits.

Differently from these works, here we investigate the possible benefits from ignoring pieces of available information concerning strategic interdependency with regard to a population of firms which may decide to ignore some essential features of strategic interaction. In order to analyse this issue, we consider a two-stage game where firms first non cooperatively choose whether or not to use the information concerning the fact that industry output corresponds to the sum of individual output of all firms, and then, again non cooperatively, set quantities to maximise profits. Both stages take place under imperfect, complete and symmetric information.

We study the plausibility of cases in which heterogeneous behavioural rules concerning the use of information related to strategic interaction co-

\footnotetext{
${ }^{2}$ Along related research lines, we may mention Kadane, Schervish and Seidenfeld (1996), showing that a Bayesian agent may find it rational to pay not to see some pieces of information. Safra and Sugarik (1993) make a similar point for cases in which agents do not choose according to the expected utility principle.
} 
exist in a given market. The fact that asymmetric firms do coexist in an industry is far from being a novelty. Asymmetry is studied as far as firms' size, goal, internal organization, and so on, is concerned. In a recent article, for instance, Chirco et al. (2013) provide a wide and up-dated literature review on theoretical, empirical, and experimental papers supporting the coexistence of heterogeneous motives for firms in a given oligopolistic market, with specific attention to the delegation of the market phase decisions to managers. More directly connected to the point of our paper, Kokovin et al. (2014) present a model in which oligopolistic and monopolistically competitive firms interact simultaneously in markets with differentiated products. In their model, however, the behavioral asymmetry across firms is linked to exogenously given firm size (see also Shimomura and Thisse, 2012). Similarly, Anderson et al. (2013) develop and use the concept of 'aggregative game' to analyze the free entry of firms in markets where oligopolistic and monopolistically competitive producers co-exist. Differently from these works, we do not assume ex-ante asymmetry in firm size, nor are we interested in the free-entry long-run equilibrium. The result we obtain is that the profit incentives of quantity-setting firms exclude the adoption of asymmetric behavioural rules at the pure-strategy subgame perfect equilibrium of a two-stage game, so that the observation of asymmetric attitudes (i.e., the simultaneous presence of oligopolistic and monopolistically competitive firms in any given industry) must be associated with the strategic uncertainty going hand in hand with the probabilistic structure of the mixed strategy equilibrium that must necessarily be accounted for when two pure-strategy equilibria exist.

We begin, in Section 2, with the analysis of the simplest case where only two firms operate in the market, characterising the map of best reply functions in oligopoly versus their counterparts in monopolistic competition. In a Digression (Section 2.2) we show that our results largely replicate (with a minor caveat) those emerging from the comparison between profit-seeking and managerial firms if managerial incentives are based on comparative profit performance, à la Miller and Pazgal (2001). At the end of this Digression, we also briefly discuss the literature suggesting that oligopolistic producers can use 'divisionalization' as a commitment to ignore relevant pieces of strategic interdependence. In Section 3, we extend the picture to allow for the presence of $n>2$ firms. In this context, we analyse the case in which all firms are either oligopolistic or monopolistically competitive, to study the individual incentive to switch towards the alternative behaviour. Subsequently we study the mixed setting where oligopolistic and monopolistically competitive firms 
coexist in a market. Here, we show that the situation in which at least one firm finds it convenient to change its behaviour concerning the consideration of strategic interdependence, is the rule: this amounts to saying that the coexistence of oligopolistic firms and monopolistically competitive firms within a given industry is not an equilibrium. Section 4 presents some extensions as well as additional considerations supporting the robustness of our model. Concluding remarks are in Section 5.

\section{The two-firm benchmark}

Two single-product firms $(i, j)$ operate in a market for differentiated products, and set output levels to maximise individual profits. We adopt a slightly simplified version of the linear demand system used by Ottaviano, Tabuchi and Thisse (2002) and Melitz and Ottaviano (2008):

$$
p_{h}=a-\beta q_{h}-\sigma Q
$$

where $p_{h}$ and $q_{h}$ are the price and output level of firm $h(h=i, j)$, while $Q$ is the overall industry output. We assume $a>0, \beta \geq 0, \sigma \geq 0$. The two varieties are homogeneous under the limiting case $\beta=0$ (in which case the price looses its index), while they become independent under the limiting case $\sigma=0$. Cost functions are $c_{h}=c q_{h}+b q_{h}^{2}$, with parameters $c, b>0$ common to both firms. Hence, firm $i$ 's profit function is $\pi_{i}=\left(p_{i}-c\right) q_{i}-b q_{i}^{2}$.

The heart of the matter is the information about the fact that $Q=q_{i}+q_{j}$. If a firm is (or chooses to be) myopic in this respect, then it writes its own demand function as in (1) and takes $Q$ as a parameter when setting the optimal choice, otherwise the demand function takes the standard form we are accustomed with from oligopoly theory:

$$
p_{i}=a-\beta q_{i}-\sigma\left(q_{i}+q_{j}\right) .
$$

To this regard, it is worth noting that one can rewrite (2) as

$$
p_{i}=a-\gamma q_{i}-\sigma q_{j}
$$

with $\gamma \equiv \beta+\sigma$, so that (3) is indeed the same demand function introduced by Bowley (1924), and then revisited by Spence (1976), Dixit (1979) and Singh and Vives (1984), inter alia. The striking difference between (1) on one side and (2) or (3) on the other is that (1) implies that firm $i$ is unaware 
of its own role in determining the industry output (and $Q$ is interpreted as a parameter when the firm sets its optimal choice), while exactly the opposite message is conveyed by (2-3). Put differently, (1) is the demand function of a firm operating in a monopolistically competitive fashion, while (2-3) is associated with a firm that is operating under oligopolistic competition. In principle, one could expect the latter to perform better than the former, precisely because of the use of available information (as against the lack thereof). Counterintuitively enough, we are setting out to show that, indeed, this is not necessarily true.

Proceeding by backward induction, we set out with the analysis of the market stage.

Let's start with the duopolistic Cournot setup, in which both firms are aware of their roles in determining the total output, and (2) is the relevant demand function. The first order condition (FOC) for the maximum individual profit of $i$ is

$$
\frac{\partial \pi_{i}}{\partial q_{i}}=a-2(b+\beta+\sigma) q_{i}-\sigma q_{j}-c=0
$$

that yields the symmetric Cournot-Nash equilibrium output level

$$
q^{s s}=\frac{a-c}{2(b+\beta)+3 \sigma}
$$

and the associated profits

$$
\pi^{s s}=\frac{(a-c)^{2}(b+\beta+\sigma)}{[2(b+\beta)+3 \sigma]^{2}}
$$

where superscripts $s s$ denote that both firms are smart. We use the label smart to indicate that a firm is aware, when it makes its choice, that the whole market output $Q$ is the sum of the individual production levels.

Next, we consider the opposite situation in which both firms are unaware of their roles when setting the optimal quantities; we label them as myopic, and the resulting FOC is

$$
\frac{\partial \pi_{i}}{\partial q_{i}}=a-2(b+\beta) q_{i}-\sigma Q-c=0 .
$$

Only after the determination of the individual optimal production, we plug $Q=q_{i}+q_{j}$ into (7), and rewrite it as

$$
a-2(b+\beta) q_{i}-\sigma\left(q_{i}+q_{j}\right)-c=0
$$


and finally impose symmetry on individual outputs and solve the FOC to obtain

$$
q^{m m}=\frac{a-c}{2(b+\beta+\sigma)} .
$$

This amounts to saying that each firm takes into account the effect of its choice in shaping industry output only after having made a decision about its own production plan. Equilibrium profits are

$$
\pi^{m m}=\frac{(a-c)^{2}(b+\beta)}{4(b+\beta+\sigma)^{2}} .
$$

Superscripts $m m$ denote that both firms are myopic.

The last case is the mixed one where $i$ is a smart firm interacting with $j$, which instead is a myopic one. Here the FOCs are

$$
\begin{gathered}
\frac{\partial \pi_{i}}{\partial q_{i}}=a-2(b+\beta+\sigma) q_{i}-\sigma q_{j}-c=0 \\
\frac{\partial \pi_{j}}{\partial q_{j}}=a-2(b+\beta) q_{i}-\sigma Q-c=0
\end{gathered}
$$

which, using $Q=q_{i}+q_{j}$, results in

$$
q_{i}^{s m}=\frac{2(a-c)(b+\beta)}{4(b+\beta)^{2}+\sigma[\sigma+6(b+\beta)]} ; q_{j}^{m s}=\frac{(a-c)[2(b+\beta)+\sigma]}{4(b+\beta)^{2}+\sigma[\sigma+6(b+\beta)]}
$$

with profits

$\pi_{i}^{s m}=\frac{4(a-c)^{2}(b+\beta)^{2}(b+\beta+\sigma)}{\left[4(b+\beta)^{2}+\sigma(\sigma+6(b+\beta))\right]^{2}} ; \pi_{j}^{m s}=\frac{(a-c)^{2}(b+\beta)[2(b+\beta)+\sigma]^{2}}{\left[4(b+\beta)^{2}+\sigma(\sigma+6(b+\beta))\right]^{2}}$.

$>$ From (12-13) it is immediate to verify that

$$
q_{i}^{s m}<q_{j}^{m s} \text { and } \pi_{i}^{s m}<\pi_{j}^{m s}
$$

i.e., the myopic firm is bigger and richer than the smart one.

An intuitive explanation for the above results can be found in the features 
of the map of best replies (11), from which we have that ${ }^{3}$

$$
\begin{aligned}
q_{i}^{*}\left(q_{j}\right) & =\frac{a-c-\sigma q_{j}}{2(b+\beta+\sigma)} \Rightarrow \frac{\partial q_{i}^{*}\left(q_{j}\right)}{\partial q_{j}}=-\frac{\sigma}{2(b+\beta+\sigma)} \\
q_{j}^{*}\left(q_{i}\right) & =\frac{a-c-\sigma q_{i}}{2(b+\beta)+\sigma} \Rightarrow \frac{\partial q_{j}^{*}\left(q_{i}\right)}{\partial q_{i}}=-\frac{\sigma}{2(b+\beta)+\sigma}
\end{aligned}
$$

with

$$
\frac{\sigma}{2(b+\beta+\sigma)}<\frac{\sigma}{2(b+\beta)+\sigma} \text { for all } b, \beta, \sigma>0 .
$$

This reveals that $q_{j}^{*}\left(q_{i}\right)$ is steeper than $q_{i}^{*}\left(q_{j}\right)$. Moreover, the intercept of $q_{j}^{*}\left(q_{i}\right)$ is higher than that of $q_{i}^{*}\left(q_{j}\right)$, since

$$
\frac{a-c}{2(b+\beta+\sigma)}<\frac{a-c}{2(b+\beta)+\sigma} \text { for all } b, \beta, \sigma>0 .
$$

Taken together, these two properties yield

Lemma 1 A myopic firm has a steeper but higher best reply function than a smart firm. Therefore, the intersection of best replies is not symmetric and reveals the presence of a strategic advantage for the firm that 'does not know', provided that the opponent does know.

The map of best replies drawn in figure 1 will help understand what is going on in this market.

\footnotetext{
${ }^{3}$ The best reply function of the myopic firm is a fictitious artifact, as literally a myopic firm is not a strategic agent. However, plugging $Q=q_{i}+q_{j}$ into (7) it is possible to obtain the expression $q_{j}^{*}\left(q_{i}\right)$, describing the behaviour of the myopic unit as if it behaved strategically.
} 


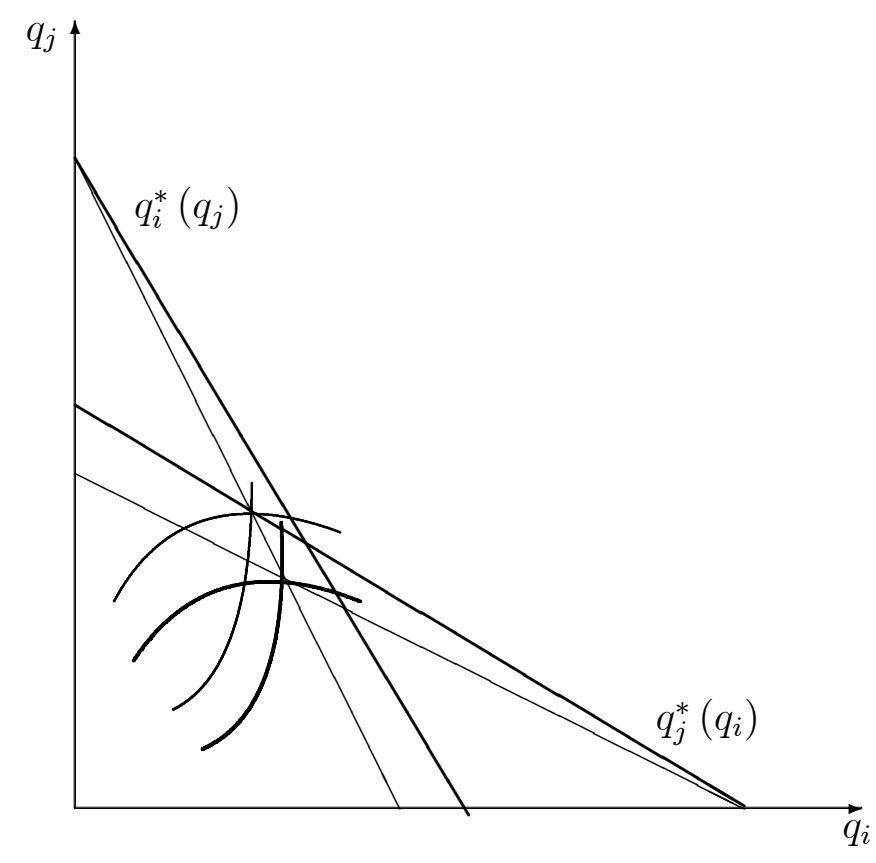

Figure 1 (Smartness vs myopia) Best reply functions in the quantity space

The thin lines are the best replies of smart (i.e., Cournot) firms, while the thick ones correspond to the behaviour of the myopic firms. The interception points of either symmetric best reply pair describe the equilibria of this market when both firms are either smart or myopic, and belong to the 45-degree line (not drawn, for simplicity). The remaining two interception points of coordinates (12) are relevant in the cases where information about the composition of industry output $Q$ is asymmetric between firms. A thick pair of isoprofit curves is drawn in correspondence of the CournotNash equilibrium. Now observe that being myopic when the rival is smart allows the myopic firm to reach an isoprofit curve necessarily higher than it would be if the opponent were equally myopic. Conversely, the smart firm finds itself in the unpleasant situation of being forced to locate onto a lower isoprofit curve as compared to what would happen if the rival were smart as well. This is the case of the thin pair of isoprofit curves associated with the interception between firm $i$ 's thin reaction function with firm $j$ 's thick reaction function. In the Digression presented in Section 2.2 below we will show 
that the mechanism at work is largely similar to what happens in models of strategic managerial delegation (Vickers, 1985; Fershtman and Judd, 1987; Sklivas, 1987; Miller and Pazgal, 2001).

Now, in order to understand whether this type of myopia or ignorance can emerge as part of the subgame perfect equilibrium, we proceed backwards to investigate the choice between knowing (or, being smart) and not knowing (or, being myopic) that $Q=q_{i}+q_{j}$ before taking FOCs. To do so, we examine the $2 \times 2$ game shown in Matrix 1, that precedes the quantity stage. Pure strategies are denoted as $s$ for smart and $m$ for myopic.

\section{Matrix 1: The first stage}

2

\begin{tabular}{cc|c|c|} 
& \multicolumn{1}{c}{$s$} & \multicolumn{1}{c}{$m$} \\
\cline { 3 - 4 } 1 & $s$ & $s$ & \multicolumn{1}{c}{$m$} \\
\cline { 3 - 4 } & & $\pi^{s s}, \pi^{s s}$ & $\pi^{s m}, \pi^{m s}$ \\
\cline { 3 - 4 } & $\pi^{m s}, \pi^{s m}$ & $\pi^{m m}, \pi^{m m}$ \\
\cline { 2 - 3 } & &
\end{tabular}

This is a pre-play stage characterised by complete, symmetric and imperfect information, i.e., simultaneous moves. Its outcome is driven by the sign of $\pi^{m s}-\pi^{s s}$ and $\pi^{m m}-\pi^{s m}$, accompanied by the ancillary inequality

$$
\pi^{s s}-\pi^{m m}=\frac{(a-c)^{2}[3(b+\beta)+4 \sigma] \sigma^{2}}{4(b+\beta+\sigma)^{2}[2(b+\beta)+3 \sigma]^{2}}>0
$$

that will univocally determine the ranking of equilibria if Matrix 1 turns out to be a coordination game with two equilibria along the main diagonal; or whether the game is a prisoners' dilemma or not in case there should exist a unique symmetric Nash equilibrium.

We may now assess $\pi^{m s}-\pi^{s s}$, to see that

$$
\pi^{m s}-\pi^{s s} \propto-\left[4(b+\beta)(b+\beta+s)^{2}+\sigma^{3}\right]<0
$$

always, so that $\pi^{s s}>\pi^{m s}$ over the entire parameter constellation.

Conversely,

$$
\pi^{m m}-\pi^{s m} \propto-\left[48 b^{3}+8 b^{2}(12 \beta-\sigma)+16 b\left(3 \beta^{2}-\beta \sigma+\sigma^{2}\right)-\sigma\left(44 \beta^{2}+68 \beta \sigma+49 \sigma^{2}\right)\right]
$$


The sign of the above expression is clearly ambiguous, meaning that the unilateral deviation from the fully myopic allocation may be or not convenient, depending on the parameter configuration. Some tedious algebra leads to show that (20) is positive (meaning that the fully myopic allocation is an equilibrium) for all $\beta$ if $5 \sigma \geq 6 b$ and for $\beta \leq \beta_{0}$ (with $\left.\beta_{0}=\left(17 \sigma^{2}+4 b \sigma-24 b^{2}+\sqrt{2 \sigma}(6 b-5 \sigma)^{3 / 2}\right) /(24 b-22 \sigma)\right)$ if $5 \sigma<6 b$. Otherwise, under the condition $5 \sigma<6 b$ joint with $\beta>\beta_{0}$, the sign is negative, meaning that the smart behaviour is the optimal response to the myopic choice of the opponent. Thus, a single and Pareto-efficient pure-strategy equilibrium at $(s, s)$, generated by the intersection of dominant strategies, exists, when parameter $\sigma$ is relatively small (namely, smaller than $6 b / 5$ ) and parameter $\beta$ is larger than a threshold level; in the opposite case, when parameter $\sigma$ is large, or in any case when parameter $\beta$ is small, a coordination game establishes, with two pure-strategy Nash equilibria in $(s, s)$ and $(m, m)$.

To interpret these results, one has to keep in mind that $\sigma$ measures the intensity of the interplay between the myopic firm and the industry as a whole. The lower is $\sigma$, the higher the degree of product differentiation. If $\sigma$ is small enough, revealing the presence of a high degree of product differentiation, then being smart is, so to speak, compulsory. Otherwise, as $\sigma$ increases we observe a variety of equilibria, including the possibility of converging to the 'fully myopic' outcome. In particular, within this parameter region, it is profitable for a given player to choose to be myopic, given the suspect that the opponent is myopic. It is true, however, that the fully myopic outcome is Pareto-inefficient for firms as compared to the fully smart outcome.

A very simple numerical simulation may help understand the point: Matrices 2(A) and 2(B) provide the firm profit levels under two different parameter configurations. Both cases consider the parameter constellation: $(a-c)^{2}=100, b=1, \beta=1$, then case (A) assumes $\sigma=1$ while case (B) assumes $\sigma=2$. In case (A), only one equilibrium exists (namely, $(s, s)$ ), while in case (B) two pure-strategy equilibria exist, $(s, s)$ and $(m, m)$. In both cases, the allocation $(m, m)$ is Pareto-inefficient for firms with respect to $(s, s)$, be it an equilibrium or not. 
Matrix 2 - Profit levels

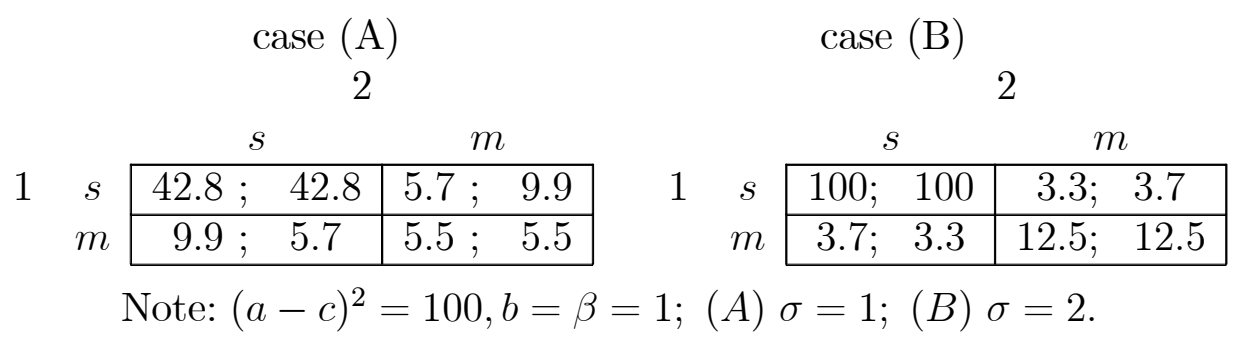

Qualitatively, the two cases shown by Matrices 2(A) and 2(B) are the only possible situations emerging in the game at hand.

\subsection{The mixed strategy equilibrium}

The arising of a coordination game for all $\sigma>2(1+\sqrt{2})(b+\beta)$ prompts for the analysis of the solution in mixed strategies. Define the probabilities that firm $i$ attaches to pure strategies $s$ and $m$ as $\mathfrak{p}_{i s}$ and $\mathfrak{p}_{i m}=1-\mathfrak{p}_{i s}$, respectively, with $\mathfrak{p}_{i s}, \mathfrak{p}_{i m} \in[0,1]$. Given the full symmetry existing a priori between firms, it will suffice to solve a single indifference condition, which can be written as follows:

$$
E \pi_{j}(s)-E \pi_{j}(m)=\mathfrak{p}_{i s} \pi^{s s}+\left(1-\mathfrak{p}_{i s}\right) \pi^{s m}-\mathfrak{p}_{i s} \pi^{m s}-\left(1-\mathfrak{p}_{i s}\right) \pi^{m m}=0
$$

where $E$ is the expected value operator, so that $E \pi_{j}(u)$ is the expected value of the profits accruing to firm $j$ if it plays strategy $u=s, m$, for any vector of probabilities attached by firm $i$ to its own pure strategies. The task that firm $i$ must perform is to solve equation (21) so as to identify the equilibrium value of probabilities $\mathfrak{p}_{i s}^{*}$ and $1-\mathfrak{p}_{i s}^{*}$ which make firm $j$ indifferent between pure strategies $s$ and $m$. This yields:

$$
\mathfrak{p}_{i s}^{*}=\frac{\pi^{s m}-\pi^{m m}}{\pi^{s m}-\pi^{m m}+\pi^{m s}-\pi^{s s}} \in(0,1) \forall \sigma>2(1+\sqrt{2})(b+\beta) .
$$

This automatically implies $\mathfrak{p}_{i m} \in(0,1)$, and

Proposition 2 A heterogeneous industry structure arises at the mixed strategy equilibrium, for all $\sigma>2(1+\sqrt{2})(b+\beta)$.

This, of course, is implicit in the coordination problem associated with multiple equilibria and imperfect information, but suffices to reveal that even in the simplest setting with two firms the amount of information concerning the composition of industry output could well differ across them. 


\subsection{Digression: strategic delegation}

Before extending our model to account for the case in which more than two firms supply the market, it is worth reporting that our problem closely resembles the choice of delegation contracts to managers in a duopoly game based on (1). The ensuing exposition can be viewed as an extension of the strategic delegation game investigated by Vickers (1985), Fershtman and Judd (1987), Sklivas (1987) and Miller and Pazgal (2001), inter alia, and may help us sketch the intuitive explanation of what will be going on in the setup on which our attention is focused.

Along this line of research, the structure of the model is a two-stage game, with delegation contracts being designed by firms' owners in the first stage and Cournot interaction taking place (among managers, if any) in the second. Define the objective function of the manager in control of firm $j$ as

$$
\mathcal{M}_{j}=\pi_{j}+\left(\theta_{j}+\xi_{j} q_{i}\right) q_{j}
$$

where variables $\left\{\theta_{j}, \xi_{j}\right\}$ are specified by shareholders in the delegation contract in order to maximise their own profits. Observe that the managerial incentive appearing in $\mathcal{M}_{j}$ contains the multiplicative effect $\xi_{j} q_{i} q_{j}$, which has not been considered so far in the literature on strategic delegation. If $\xi_{j}=0$, the managerial objective function (23) indeed coincides with that appearing in Vickers (1985). ${ }^{4}$ If instead $\theta_{j}=0$, then (23) is equivalent to the delegation scheme used by Miller and Pazgal (2001), based on comparative profit performance. In their paper, Miller and Pazgal suppose that the manager of firm $j$ be rewarded in proportion to

$$
\widehat{\mathcal{M}}_{j}=\pi_{j}-\zeta_{j} \pi_{i}
$$

where $\zeta_{j}$ is to be chosen by owners so as to maximise $\pi_{j}$. Observe that the first order condition describing the behaviour of manager $j$ is

$$
\frac{\partial \widehat{\mathcal{M}}_{j}}{\partial q_{j}}=\frac{\partial \pi_{j}}{\partial q_{j}}-\zeta_{j} \frac{\partial \pi_{i}}{\partial q_{j}}=\frac{\partial \pi_{j}}{\partial q_{j}}-\zeta_{j} \sigma q_{i}=0
$$

yielding the best reply function:

$$
q_{j}^{*}\left(q_{i}\right)=\frac{a-c-\sigma\left(1-\zeta_{j}\right) q_{i}}{2(b+\beta+\sigma)} .
$$

\footnotetext{
${ }^{4}$ In such a case, it also coincides with the incentive scheme used by Fershtman and Judd (1987) and Sklivas (1987), as shown in Lambertini and Trombetta (2002, Appendix A, p. 371).
} 
At the first stage, owners noncooperatively and simultaneously maximise profits w.r.t. the delegation contract variable $\zeta_{j}$, whereby the unique symmetric Nash equilibrium is

$$
\zeta^{*}=\frac{\sigma}{2(b+\beta)+\sigma} .
$$

Now, back to our approach, manager $j$ must choose $q_{j}$ so as to maximise $\mathcal{M}_{j}$ in (23). The resulting FOC is the following:

$$
\frac{\partial \mathcal{M}_{j}}{\partial q_{j}}=a-2(b+\beta+\sigma) q_{i}-\left(\sigma+\xi_{j}\right) q_{j}-c+\theta_{j}=0
$$

producing the best reply function:

$$
q_{j}^{*}\left(q_{i}\right)=\frac{a-c+\theta_{j}-\left(\sigma-\xi_{j}\right) q_{i}}{2(b+\beta+\sigma)}
$$

which coincides with (26) if $\theta_{i}=\theta_{j}=0$ and $\xi_{j}=\sigma \zeta_{j}$. Indeed, so it turns out at the subgame perfect equilibrium, where the profit maximising contracts chosen by managers are denoted by

$$
\xi_{j}^{*}=\xi_{i}^{*}=\frac{\sigma^{2}}{2(b+\beta)+\sigma}=\sigma \zeta^{*}
$$

in correspondence of $\theta_{i}=\theta_{j}=0$. This shows that:

Lemma 3 Under Cournot competition, and for any admissible degree of product differentiation, a delegation contract based on comparative profit performance is equivalent to requiring the manager to maximise an objective function corresponding to the sum of the firm's own profits plus the delegation variable multiplied by the product of firms' output levels.

This is an intuitive consequence of the fact that the partial derivative of firm $i$ 's profit function w.r.t. firm $j$ 's output is in fact the derivative of the product of the two output levels. Therefore, $\mathcal{M}_{j}$ and $\widehat{\mathcal{M}}_{j}$ must necessarily generate exactly the same subgame perfect equilibrium.

Moreover, note that the vertical intercept of the best reply in (29) is $\left(a-c+\theta_{j}\right) /[2(b+\beta+\sigma)]$, while the slope is

$$
\frac{\partial q_{j}^{*}\left(q_{i}\right)}{\partial q_{i}}=-\frac{\sigma-\xi_{j}}{2(b+\beta+\sigma)}<0 \forall \sigma>\xi_{j}
$$


otherwise the reaction function of firm $j$ becomes increasing in the rival's output level. Accordingly, suppose $\sigma>\xi_{j}$. The overall effect of this delegation contract is therefore the combination of (i) an outward shift of firm $j$ 's best reply function for all $\theta_{j}>0$, as we know from Vickers (1985), and (ii) a rotation of the (decreasing) best reply, since the latter becomes flatter as $\xi_{j}$ increases. If $\xi_{j}=\sigma$, then $\partial q_{j}^{*}\left(q_{i}\right) / \partial q_{i}=0$ and the reaction function is totally flat, the manager playing then a dominant strategy in the market subgame. Both effects concur in moving the best reply function, grossly speaking, in the same direction, provoking thus an output expansion on the part of firm $j$, all else equal.

This situation is represented in figure 2, which clearly resembles figure $1 .^{5}$ The thin lines are the best replies of pure profit-seeking agents setting $\theta_{j}=\xi_{j}=0$, while the thick ones are those of managerial firms setting $\theta_{j}>0$ and $\xi_{j} \in(0, \sigma)$. Isoprofit curves are drawn only in correspondence of the Cournot-Nash equilibrium among pure profit-seeking entrepreneurial units. The equilibria of the asymmetric cases, in which a managerial firm interacts with an entrepreneurial rival, are identified by the intersection points of a 'thick' best reply with a 'thin' one. In either of these points, delegation clearly improves the position of the firm which has hired a manager vis à vis that of the entrepreneurial counterpart by virtue of the outward movement of the reaction function, causing an expansion of the managerial firm's production and a corresponding restriction of the entrepreneurial's one.

As we have seen, a somewhat analogous mechanism is at work in the model we are focussing upon, concerning the use of information on industry output and its effects on strategic interaction. Substantially, any instrument allowing a firm to move its reaction function outwards is, all else equal, profitenhancing, and is therefore liable to be used to this aim. This Digression is relevant to our argument, precisely because it provides an example of a meaningful mechanism device through which a firm can replicate the commitment to disregard strategic interdependence: such mechanism can be represented by the managerial delegation with a manager remuneration based on (23).

\footnotetext{
${ }^{5}$ Except for the fact that here delegation also affects the intercepts of best replies. Moreover, for the sake of simplicity, a single pair of isoprofit curves is drawn, in correspondence of the intersection of the reaction functions of pure profit-seeking firms.
} 


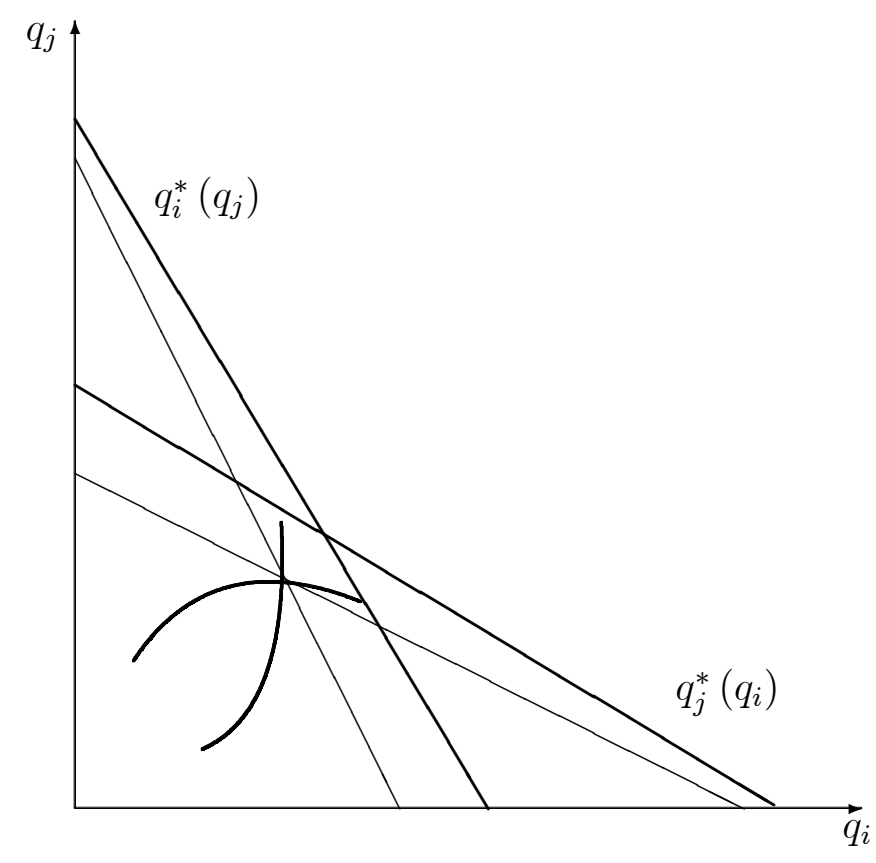

Figure 2 (Delegation game) Best reply functions in the quantity space

A different device through which a producer can replicate the commitment to disregard strategic interdependence is suggested by the literature that studies 'divisionalization', that is, the creation by a firm of divisions that compete independently in the market (see e.g., Baye et al., 1996; Ziss, 1998). The idea is that a multiproduct firm, aware of the interdependencies among its products, may delegate the choices concerning any single product to an independent manager unaware of those interdependencies. Divisionalization entails pros and cons, but the strategic incentive for a firm to divisionalize rests on a commitment to more aggressive behavior, which increases the firm's market share at the expenses of its rivals. A model in which divisionalization can arise as the optimal choice for a big (oligopolistic) firm that competes with a fringe of small monopolistically competitive rivals is presented by Kokovin et al. (2014). In their model, depending on the market demand configuration, the big firm may find it convenient to be broken down into horizontal profit-maximizing divisions that disregard their interdependencies and behave like monopolistically competitive units. 


\section{The $N$-firm setting}

Consider now the more general case where the same market (i.e., leaving unmodified the initial assumptions concerning the demand system and technology), is served by $N$ single-product firms. In the remainder, we will consider two different but closely related perspectives. The first is that where a single firm chooses whether to be smart or myopic given a homogeneous choice by the remaining $N-1$ firms. This exercise will enlighten us as to the existence (or lack) of an individual profit incentive to deviate from the fully symmetric outcome in which the entire population of firms in the industry is alternatively smart or myopic. The second perspective will consider a generic composition of the industry, assuming that $K=1,2,3, \ldots k$ firms are myopic and the remaining $N-K=k+1, k+2, k+3, \ldots n$ are smart. Our aim will be to see whether there exists a stable partition of the population of firms into a smart group and a myopic one.

\subsection{Unilateral deviations}

To begin with, we may briefly review the 'fully smart industry equilibrium', that is, the Cournot-Nash outcome generated by the system of demand functions:

$$
p_{i}=a-\beta q_{i}-\sigma\left(q_{i}+\sum_{j \neq i} q_{j}\right) .
$$

The profit function of firm $i$ being defined as $\pi_{i}=\left(p_{i}-c\right) q_{i}-b q_{i}^{2}$, one has to solve the set of $N$ FOCs:

$$
\frac{\partial \pi_{i}}{\partial q_{i}}=a-2(b+\beta+\sigma) q_{i}-\sigma \sum_{j \neq i} q_{j}-c=0
$$

in order to find the vector of symmetric equilibrium outputs:

$$
q^{s s}(n)=\frac{a-c}{2(b+\beta)+\sigma(n+1)}
$$

and profits:

$$
\pi^{s s}(n)=\frac{(a-c)^{2}(b+\beta+\sigma)}{[2(b+\beta)+\sigma(n+1)]^{2}} .
$$

Now we turn our attention to individual deviations from this symmetric outcome. Consider the perspective of a single firm assessing the profitability 
of defecting unilaterally from (34) and become myopic. In such a case, firm $i$ faces (45), while any competitor $j \neq i$ faces (32). The resulting FOCs are:

$$
\frac{\partial \pi_{i}}{\partial q_{i}}=a-2(b+\beta) q_{i}-\sigma Q-c=0
$$

for the single myopic firm, and

$$
\frac{\partial \pi_{j}}{\partial q_{j}}=a-2(b+\beta+\sigma) q_{j}-\sigma Q_{-j}-c=0
$$

for each of its $n-1$ smart rivals. On the r.h.s. of the above equation, $Q_{-j}=\sum_{\ell \neq j} q_{\ell}$. The above system is solved by a vector of outputs composed by a single quantity $q^{m s}$ and $n-1$ quantities $q^{s m}$ :

$$
\begin{aligned}
& q^{m s}(1, n-1)=\frac{(a-c)[2(b+\beta)+\sigma]}{4\left(b^{2}+\beta^{2}\right)+\sigma[\sigma+2 b(n+1)]+2 \beta[4 b+\sigma(n+1)]} \\
& q^{s m}(n-1,1)=\frac{2(a-c)(b+\beta)}{4\left(b^{2}+\beta^{2}\right)+\sigma[\sigma+2 b(n+1)]+2 \beta[4 b+\sigma(n+1)]}
\end{aligned}
$$

with

$q^{m s}(1, n-1)-q^{s m}(n-1,1)=\frac{(a-c) \sigma}{4\left(b^{2}+\beta^{2}\right)+\sigma[\sigma+2 b(n+1)]+2 \beta[4 b+\sigma(n+1)]}>0$.

That is,

Lemma 4 If all rivals are smart, being individually myopic allows a single firm to expand output, irrespective of the overall number of firms in the industry.

The associated profits are

$$
\pi^{m s}(1, n-1)=\frac{(a-c)^{2}[2(b+\beta)+\sigma]^{2}(b+\beta)}{\left[4(b+\beta)^{2}+\sigma(\sigma+2(b+\beta)(n+1))\right]^{2}}
$$

and

$$
\pi^{s m}(n-1,1)=\frac{4(a-c)^{2}(b+\beta)^{2}(b+\beta+\sigma)}{\left[4(b+\beta)^{2}+\sigma(\sigma+2(b+\beta)(n+1))\right]^{2}} .
$$


The unilateral deviation from smart to myopic is convenient if and only if $\pi^{m s}(1, n-1)>\pi^{s s}(n)$ : it can be easily checked that such a inequality is quadratic in $n$, and it is met iff:

$$
(b+\beta)\left[\sigma^{2}(n(n-2)-4)-4(b+\beta)(b+\beta+\sigma)\right]-\sigma^{3}>0 .
$$

The l.h.s. of (42) is nil at

$$
n_{ \pm}=\frac{\sigma(b+\beta) \pm[2(b+\beta)+\sigma] \sqrt{(b+\beta)(b+\beta+\sigma)}}{\sigma(b+\beta)} .
$$

Notice that a necessary but not sufficient condition for (42) to apply is $n \geq$ 4 , since otherwise $n(n-2)-4<0$ and therefore the entire expression is necessarily negative (in line with what we already know from the initial analysis of the two-firm case); notice also that $n_{-}<4$ everywhere, while $n_{+} \geq 4$ if

$$
(b+\beta+\sigma)[2(b+\beta)+\sigma] \geq 9(b+\beta) \sigma^{2} .
$$

The analysis of this case boils down to:

Lemma 5 In the region identified by $n>n_{+} \equiv 1+(1+2(b+\beta) / \sigma) \sqrt{1+\sigma /(b+\beta)}$ and $(b+\beta+\sigma)[2(b+\beta)+\sigma] \geq 9(b+\beta) \sigma^{2}$, the unilateral deviation from the fully smart outcome is profitable.

That is to say, for a firm to find it convenient to be myopic in front of a population of smart rivals, the industry must be sufficiently fragmented (and this must be accompanied by other conditions connecting cost and demand parameters).

Now it's time to deal with the opposite scenario, that is, the case where a single firm, say, firm $i$, deviates from the fully myopic outcome to become smart. The relevant demand system in the fully myopic case is

$$
p_{i}=a-b q_{i}-\sigma Q
$$

which generates the following FOC:

$$
\frac{\partial \pi_{i}}{\partial q_{i}}=a-2(b+\beta) q_{i}-\sigma Q-c=0 .
$$

Imposing symmetry across firms and replacing $Q$ with $n q$, one obtains the equilibrium output

$$
q^{m m}(n)=\frac{a-c}{2(b+\beta)+n \sigma}
$$


and the corresponding profits

$$
\pi^{m m}(n)=\frac{(a-c)^{2}(b+\beta)}{[2(b+\beta)+n \sigma]^{2}} .
$$

If firm $i$ conjectures to become individually smart, her demand function writes as in (32), while any of the remaining $n-1$ myopic rivals faces the demand function (45), so that the FOCs are:

$$
\frac{\partial \pi_{i}}{\partial q_{i}}=a-2(b+\beta+\sigma) q_{i}-\sigma Q_{-i}-c=0
$$

for the single smart firm, and

$$
\frac{\partial \pi_{j}}{\partial q_{j}}=a-2(b+\beta) q_{j}-\sigma Q-c=0
$$

for each of its $n-1$ myopic rivals. Imposing symmetry among the latter, the equilibrium outputs obtain:

$$
\begin{aligned}
& q^{s m}(1, n-1)=\frac{2(a-c)(b+\beta)}{4\left(b^{2}+\beta^{2}\right)+\sigma[\sigma+2 b(n+1)]+2 \beta[4 b+\sigma(n+1)]} \\
& q^{m s}(n-1,1)=\frac{(a-c)[2(b+\beta)+\sigma]}{4\left(b^{2}+\beta^{2}\right)+\sigma[\sigma+2 b(n+1)]+2 \beta[4 b+\sigma(n+1)]}
\end{aligned}
$$

with $q^{s m}(1, n-1)<q^{m s}(n-1,1)$, and the resulting profits are

$$
\pi^{s m}(1, n-1)=\frac{4(a-c)^{2}(b+\beta)^{2}(b+\beta+\sigma)}{\left[2(b+\beta)(2(b+\beta)+(n+1) \sigma)+(n-1) \sigma^{2}\right]^{2}}
$$

and

$$
\pi^{m s}(n-1,1)=\frac{(a-c)^{2}(b+\beta)[2(b+\beta)+\sigma]^{2}}{\left[2(b+\beta)(2(b+\beta)+(n+1) \sigma)+(n-1) \sigma^{2}\right]^{2}} .
$$

The unilateral deviation from the fully myopic setting is profitable iff

$$
\pi^{s m}(1, n-1)-\pi^{m m}(n) \propto 4(b+\beta)[b+\beta+\sigma]-(n-1)^{2} \sigma^{2}>0 .
$$

The above condition is satisfied for all

$$
0<\sigma<\frac{2(1+\sqrt{2+n(n-2)})(b+\beta)}{(n-1)^{2}} .
$$


Note that, if $n=2$, the above conclusion obviously coincides with the result derived in section 2. Also observe that the upper bound in (55) monotonically decreases in $n$. Overall, this leads to the following conclusion: if the impact of aggregate industry output on individual performance - as measured by parameter $\sigma$ - is not too relevant, the unilateral deviation from the fully myopic outcome is profitable. On the contrary, if parameter $\sigma$ is large (revealing the presence of a low degree of product differentiation), then the unilateral deviation from the fully myopic equilibrium is not profitable.

Clearly, condition (54) may be written also as $(n-1)^{2}<4(b+\beta)(b+\beta+$ $\sigma) / \sigma^{2}$. Hence,

Lemma 6 In the region identified by $n<1+2 \sqrt{(b+\beta)(b+\beta+\sigma)} / \sigma$, the unilateral deviation from the fully myopic outcome is profitable

This means that the number of firms serving the market has to be limited, for the unilateral deviation from the fully myopic outcome being individually profitable. In such a case, the fully myopic setting is not an equilibrium. The larger the number of firms is, the more likely that the fully myopic setting is an equilibrium, where the unilateral deviation is not profitable. In any case, the fully myopic setting is Pareto inefficient for firms, irrespective of whether or not the individual deviation is profitable.

\subsubsection{Is there a stable partition?}

Consider the case in which the industry consists of $K=1,2,3, \ldots k$ myopic firms and $N-K=k+1, k+2, k+3, \ldots n$ smart ones. To characterise the game, it suffices to look at two of these firm, a smart one, say, $i$, and a myopic one, say, $j$. Their respective demand functions are:

$$
\begin{gathered}
p_{i}=a-\beta q_{i}-\sigma\left(q_{i}+\sum_{\ell \neq i} q_{\ell}\right) \\
p_{j}=a-\beta q_{j}-\sigma Q
\end{gathered}
$$

The FOCs are:

$$
\begin{gathered}
\frac{\partial \pi_{i}}{\partial q_{i}}=a-2(b+s) q_{i}-s\left(q_{j}+Q_{K-j}+Q_{N-K-i}\right)-c=0 \\
\frac{\partial \pi_{j}}{\partial q_{j}}=a-2(b+\beta) q_{j}-s Q-c=0
\end{gathered}
$$


where $Q_{K-j}$ it the collective output of the myopic group (except $j$ ) and $Q_{N-K-i}$ is the collective output of the smart group (except $i$ ). We may now plug $Q=\sum_{\ell=1}^{n} q_{\ell}$ into the second and impose symmetry within each sub-population of firms to solve the system and find the equilibrium outputs

$$
\begin{aligned}
& q^{s m}(n-k, k)=\frac{2(a-c)(b+\beta)}{4\left(b^{2}+\beta^{2}\right)+\sigma[\sigma k+2 \beta(n+1)]+2 b[4 \beta+(n+1) \sigma]}(58) \\
& q^{m s}(k, n-k)=\frac{(a-c)[2(b+\beta)+\sigma]}{4\left(b^{2}+\beta^{2}\right)+\sigma[\sigma k+2 \beta(n+1)]+2 b[4 \beta+(n+1) \sigma]}\left(\begin{array}{c}
\sigma \\
\sigma
\end{array}\right)
\end{aligned}
$$

and the corresponding profits ${ }^{6}$

$$
\begin{aligned}
& \pi^{s m}(n-k, k)=\frac{4(a-c)^{2}(b+\beta)^{2}(b+\beta+\sigma)}{\left[4(b+\beta)^{2}+\sigma(\sigma k+2(b+\beta)(n+1))\right]^{2}} \\
& \pi^{m s}(k, n-k)=\frac{(a-c)^{2}(b+\beta)[2(b+\beta)+\sigma]^{2}}{\left[4(b+\beta)^{2}+\sigma(\sigma k+2(b+\beta)(n+1))\right]^{2}} .
\end{aligned}
$$

As before, also here we have $q^{m s}(k, n-k)>q^{s m}(n-k, k)$ and $\pi^{m s}(k, n-k)>$ $\pi^{s m}(n-k, k)$ irrespective of the numerosity and composition of the population of firms. However,

$$
\begin{gathered}
\frac{\partial\left[\pi^{m s}(k, n-k)-\pi^{s m}(n-k, k)\right]}{\partial k}= \\
-\frac{2(a-c)^{2}(b+\beta) \sigma^{4}}{\left[4(b+\beta)^{2}+\sigma(\sigma k+2(b+\beta)(n+1))\right]^{3}}<0,
\end{gathered}
$$

i.e., the profit differential monotonically decreases as the number of myopic firms increases.

To carry out our analysis, we borrow from coalition theory a standard method that has already been used successfully in the theory of industrial organization to study the optimal size of cartels operating in markets where a competitive fringe is also present (see d'Aspremont et al., 1983; Donsimoni, Economides and Polemarchakis, 1986).

We want to establish whether there exists a number $k \in[1, n-1]$ such that the partition $\{K, N-K\}$ is stable. This requires two incentive compatibility constraints to be simultaneously satisfied:

\footnotetext{
${ }^{6}$ It can be easily verified that, if $k=0,(58)$ and (60) coincide with (34) and (35), respectively. If instead $k=n,(59)$ and (61) coincide with (47) and (48), respectively. The same applies for unilateral deviation profits, using $k=1$ and $k=n-1$.
} 
A] it must not be individually profitable for a myopic firm in $K$ to abandon it and join the set of smart firms (in which case the number of myopic firms would decrease to $k-1$ while that of smart ones would increase to $n-k+1)$; and

B] likewise, it must not be individually profitable for a smart firm in $N-K$ to quit this group to become a myopic one (in which case the number of myopic firms would increase to $k+1$ while that of smart ones would decrease to $n-k-1)$.

Conditions $\mathrm{A}$ and $\mathrm{B}$ are respectively equivalent to saying that there must exists a number $k \in[1, n-1]$ such that

$$
\begin{gathered}
\pi^{m s}(k, n-k) \geq \pi^{s m}(n-k+1, k-1) \Leftrightarrow \\
\frac{[2(b+\beta)+\sigma]^{2}}{\left[4(b+\beta)^{2}+\sigma(\sigma k+2(b+\beta)(n+1))\right]^{2}} \geq \\
\frac{4(b+\beta)(b+\beta+\sigma)}{\left[4(b+\beta)^{2}+\sigma(\sigma(k-1)+2(b+\beta)(n+1))\right]^{2}}
\end{gathered}
$$

and

$$
\begin{gathered}
\pi^{s m}(n-k, k) \geq \pi^{m s}(k+1, n-k-1) \Leftrightarrow \\
\frac{4(b+\beta)(b+\beta+\sigma)}{\left[4(b+\beta)^{2}+\sigma(\sigma k+2(b+\beta)(n+1))\right]^{2}} \geq \\
\frac{[2(b+\beta)+\sigma]^{2}}{\left[4(b+\beta)^{2}+\sigma(\sigma(k+1)+2(b+\beta)(n+1))\right]^{2}}
\end{gathered}
$$

be simultaneously satisfied.

Inequality (63) is met iff

$$
\begin{gathered}
\Psi=\sigma^{4}(k-1)^{2}-4 \sigma^{3}(b+\beta)[n-k(n-1)]+ \\
4 \sigma^{2}(b+\beta)^{2}[n(n-2)-4]-32 \sigma(b+\beta)^{3}-16(b+\beta)^{4} \geq 0
\end{gathered}
$$

which holds true for all $k$ outside the interval identified by the roots of $\Psi=0$ :

$$
\widetilde{k}_{ \pm}=\frac{2\left[-\sigma(n-1)(b+\beta)+\sigma^{2} \pm(2(b+\beta)+\sigma) \sqrt{(b+\beta)(b+\beta+\sigma)}\right]}{\sigma^{2}}
$$


with $\widetilde{k}_{-}<0$ for all admissible values of $\{b, n, \beta, \sigma\}$, and $\widetilde{k}_{+} \geq 2$ iff

$$
4(b+\beta)(b+\beta+\sigma)[2(b+\beta)+\sigma]^{2} \geq \sigma^{2}[2(n-1)(b+\beta)+\sigma]^{2} .
$$

The necessary and sufficient condition for (64) to hold is

$$
\begin{gathered}
\Omega=-\sigma^{4} k^{2}-4 \sigma^{3}(b+\beta)[k(n-1)-1] \\
-4 \sigma^{2}(b+\beta)^{2}[n(n-2)-4]+32 \sigma(b+\beta)^{3}+16(b+\beta)^{4} \geq 0
\end{gathered}
$$

which in turn is satisfied by all $k$ lying inside the interval of the roots of $\Omega=0$ :

$$
\widehat{k}_{ \pm}=\frac{2[-\sigma(n-1)(b+\beta) \pm(2(b+\beta)+\sigma) \sqrt{(b+\beta)(b+\beta+\sigma)}]}{\sigma^{2}}
$$

with $\widehat{k}_{-}<0$ for all admissible values of $\{b, n, \beta, \sigma\}$, and $\widehat{k}_{+} \geq 2$ in the parameter region identified by

$$
(b+\beta)(b+\beta+\sigma)[2(b+\beta)+\sigma]^{2} \geq \sigma^{2}[(n-1)(b+\beta)+\sigma]^{2} .
$$

Now, comparing (67) and (70), one should verify whether there exist a common parameter range in which (63) and (64) are simultaneously satisfied by some admissible integer $k^{7}$ It is quickly verified that this is never the case, by observing that

$$
\widetilde{k}_{+}-\widehat{k}_{+}=1 \text {, }
$$

so that we can formulate our result, in the following terms:

Proposition 7 The intervals of $k$ wherein, respectively,

$$
\begin{aligned}
& \pi^{m s}(k, n-k) \geq \pi^{s m}(n-k+1, k-1) ; \\
& \pi^{s m}(n-k, k) \geq \pi^{m s}(k+1, n-k-1),
\end{aligned}
$$

are disjoint for all admissible values of parameters $\{b, n, \beta, \sigma\}$. Consequently, there exists no stable partition of the population of firms between the smart and the myopic group.

\footnotetext{
${ }^{7}$ Needless to say, if condition (67) is not met, the analysis falls into the case of unilateral deviation from the fully myopic allocation. Similarly, if (70) is not met, the analysis falls in the case of unilateral deviation from the fully smart situation.
} 
We have already proved that the fully-myopic allocation, and the fullysmart allocation can be stable equilibrium or not, depending on parameter configuration. The final step of our argument consists in proving the following

Proposition 8 For any given parameter configuration it is impossible that the fully-smart allocation and the fully-myopic allocation are simultaneously unstable. Consequently, for any given parameter configuration, the instability of the fully-smart allocation implies that the fully myopic allocation is an equilibrium, and the instability of the fully-myopic allocation implies that the fully-smart allocation is an equilibrium.

Proof. The proof is straightforward. The instability of the situation in which $k=0$ requires $n>n_{+}$(as given by (43)) as a necessary condition, that is: $n>$ $[\sigma(b+\beta)+[2(b+\beta)+\sigma] \sqrt{D}] /(\sigma(b+\beta))$ where $D=(b+\beta)(b+\beta+\sigma)$, that is

$$
(n-1)>\frac{[2(b+\beta)+\sigma] \sqrt{D}}{\sigma(b+\beta)}
$$

The instability of the situation in which $k$ is equal to $n$, as shown by (55), requires $\sigma<2(1+\sqrt{2+n(n-2)})(b+\beta) /(n-1)^{2}$ which, in the presence of the constraints holding in this model, corresponds to

$$
(n-1)<\frac{2 \sqrt{D}}{\sigma}
$$

Now, (73) may be written as $(n-1) \sigma / \sqrt{D}<2$, while $(72)$ is $(n-1) \sigma / \sqrt{D}>$ $2+\sigma /(b+\beta)$, and clearly the two conditions can not hold simultaneously.

Taking into consideration the last two Propositions, we can conclude that no stable partition of firms exists, such that heterogeneous behaviours are simultaneously present in the industry in pure strategies. At the same time, the simultaneous instability of the full myopic and the full smart allocation is impossible. These properties prevent the perpetual mobility of firms across smart and myopic groups to be observable. The fully-smart or the fullymyopic allocation (or both) are stable. Furthermore, recalling the Paretoefficiency properties of different allocation, we can state:

Corollary 9 If firms can choose whether or not to account for strategic interdependence, that is, they can choose whether to behave as smart (oligopolistic) or myopic (monopolistically competitive) firms, then three alternative scenarios are possible: 
1. the unique equilibrium is an oligopolistic one in which all firms choose to take into account strategic interdependence (fully smart allocation);

2. the unique equilibrium is a monopolistically competitive one in which all firms choose to disregard strategic interdependence (fully myopic allocation);

3. both the fully smart and the fully myopic allocations are equilibria.

In all cases, the fully myopic allocation is Pareto inefficient for firms with respect to the fully smart allocation, irrespective of the equilibrium configuration.

Table 1 provides a simple numerical simulation, illustrating the different cases that may arise. In case (A), the fully-smart allocation is the only equilibrium situation: in this case, even if the allocation occurred in which all firms are myopic $(k=4)$, an individual incentive would exist for a myopic firm to behave as smart $(206.7>206.6$ ), but such an allocation (with 3 myopic and 1 smart firms) would again be unstable, since a unilateral incentive would still exist for a myopic to behave as smart (206.90>206.8), and so on. In the case where all firms are smart, no incentive exists to change one's own behaviour $(207.3<207.4)$. In case $(B)$, both the fully smart and the fully myopic allocations are equilibria, in the sense that no individual profit incentive to change unilaterally the behaviour is operating. It remains true that the situation in which all firms are myopic is inefficient for them as compared to the case in which all firms are smart. Notice also that, starting from the situation in which $k=3$, an individual incentive would exist for a smart (the smart, to be precise) firm to behave as myopic $(27.7>27.6)$; at the same time, an individual incentive exists for a myopic firm to change its behaviour (given the others' behaviours), since $31.2>31.1 .^{8}$ Finally, in scenario (C),

\footnotetext{
${ }^{8}$ Clearly, if a smart firm turns its behaviour into myopic, and simultaneoulsy a myopic firm turns its behaviour into smart, one would observe a stable partition, as far as the size of the two different groups of firms is concerned. Such an argument could support the empirical evidence that the partition of a mixed population of firms within the same industry may appear to be stable. However, this situation can not be interpreted as a stable equilibrium - at least if one focuses on pure strategies. On the other hand, the mixed population outcome can be interpreted as the empirical counterpart of an equilibrium in mixed strategy, which clearly exists in cases replicating scenario (B). The formal proof of the existence of a mixed strategy Nash equilibrium has been provided in subsection 2.1 for the 2 player case and it is omitted for the sake of brevity in the general setting with $n$ players.
} 
the only stable allocation is that of a generalised myopia, although it is Pareto-inefficient. The reason why the efficient situation $(k=0)$ is unstable is clear: starting from a situation in which all firms are smart, an individual incentive for a firm to change its behaviour operates, provided all other firms do not change their behaviour $(2869>2861)$. The situation depicted by $(\mathrm{C})$ clearly resembles the prisoners' dilemma story: the efficient allocation is not an equilibrium due to the individual incentive to deviate; hence, if all players deviate, the (Pareto-inefficient) equilibrium establishes.

\begin{tabular}{|c|c|c|c|c|c|c|}
\hline & $k=0$ & $k=1$ & $k=2$ & $k=3$ & $k=4$ & $k=5$ \\
\hline A) $\begin{aligned} n & =4, \\
\beta & =.005 \\
\beta & =.1\end{aligned}$ & (4) $\pi^{s}=207.4$ & $\begin{array}{l}(3) \pi^{s}=207.1 \\
\text { (1) } \pi^{m}=207.3\end{array}$ & $\begin{array}{l}(2) \pi^{5}=206.9 \\
(2) \pi^{m}=207.0\end{array}$ & $\begin{array}{l}\text { (1) } \pi^{5}=206.7 \\
\text { (3) } \pi^{m}=206.8\end{array}$ & $(4) \pi^{m}=206.6$ & \\
\hline B) $\begin{aligned} n & =4, \\
\beta & =.01 \\
\beta & =1\end{aligned}$ & $\begin{array}{c}(4) \pi^{5}=40.8 \\
\end{array}$ & $\begin{array}{l}(3) \pi^{s}=35.5 \\
\text { (1) } \pi^{m}=40.0\end{array}$ & $\begin{array}{l}(2) \pi^{5}=31.2 \\
(2) \pi^{m}=35.1\end{array}$ & $\begin{array}{l}\text { (1) } \pi^{s}=27.6 \\
\text { (3) } \pi^{m}=31.1\end{array}$ & (4) $\pi^{m}=27.7$ & \\
\hline $\begin{aligned} n & =5, \\
\text { C) } \sigma & =.001 \\
\beta & =.0001\end{aligned}$ & $(5) \pi^{s}=2861$ & $\begin{array}{c}(4) \pi^{5}=876 \\
(1) \pi^{m}=2869\end{array}$ & $\begin{array}{c}(3) \pi^{5}=419 \\
(2) \pi^{m}=1371\end{array}$ & $\begin{array}{l}\text { (2) } \pi^{5}=244 \\
\text { (3) } \pi^{m}=800\end{array}$ & $\begin{array}{l}(1) \pi^{s}=160 \\
(4) \pi^{m}=524\end{array}$ & $(5) \pi^{m}=396$ \\
\hline
\end{tabular}

Table 1 


\section{Robustness and extensions}

The model can be modified, to take into consideration asymmetric costs. For instance, in the two-player case it is very simple to compute the outcome, and to evaluate the equilibrium outcomes, if one firm has $c=0$, and the other $c>0$; or the case in which $\beta$ is nil for one firm and positive for the other. We have stretched the model along these routes, to understand whether exogenous asymmetry across firms could support heterogeneous behavioural rules at equilibrium. As a matter of fact, in no cases (under the simple assumptions at hand) we have found that the mixed population can be a stable equilibrium in pure strategies. These elements provide robustness to our theoretical conclusions. Of course (and trivially), there is a condition whereby a mixed population can be an equilibrium, namely, that the collection of information by at least part of the firms is a costly activity: in such a situation, for sufficiently large information cost, some firms may find it convenient to behave myopically, while other firms find it convenient to behave smartly.

In general, our model rules out the coexistence of heterogeneous behaviours across firms serving a market as an equilibrium - at least in pure strategies - when firms can choose endogenously whether or not to consider the interdependence links, and do so for free. However, one could argue that in some markets in the real world oligopolistic behaviour coexists with a monopolistically competitive one. Just to give a few examples, let us think of consumer electronics. This market is indeed simultaneously supplied by large firms with well established brands commanding high mark-ups, and totally aware of strategic interaction, as well as by other producers whose nature is typically that of a population of monopolistically competitive firms, with brand counting much less or nothing at all and mark-ups consequently a lot lower, if not nil. The film industry may be an additional example: a few large (world-wide) film production companies (adopting a neatly oligopolistic behaviour) coexist with several small (generally local) producers, that usually behave as monopolistic firms within specific niches. Again, we can think of book markets, which are served by both large chainstores and small specialised shops: likely, the former behave as oligopolistic and the latter as monopolistically competitive sellers. Three considerations are in order. First, we could argue that these empirical situations find a theoretical counterpart in our model, as we show that an equilibrium in mixed strategy exists, when two pure-strategy equilibria are present. Second, we would like to mention 
that in those markets where (large) oligopolistic firms coexist with (small) monopolistically competitive providers, one is typically concerned about the possible disappearance of small shops serving specific niches, entailing a loss of product variety and a detrimental effect on consumer surplus. From this standpoint, our model could lend support to such concern, showing that the mixed setting is not stable, and the fully oligopolistic setting provides larger profits to firms; however, it goes without saying that our present model takes the number of operative firms in a market as given, and it does not investigate exit decision. Third, we have already recalled that a recent, specific literature investigates markets in which large oligopolistic firms co-exist with a fringe of atomistic monopolistically competitive rivals (see, e.g., Anderson et al., 2013; Parenti, 2013; Shimomura and Thisse, 2014). In this literature, however, the different nature of firms is exogenously given as monopolistically competitive firms cannot turn their behavior into oligopolistic. At most, oligopolistic firms may choose to divisionalize with divisions then behaving as monopolistic competitors.

The instability of the mixed setting could represent a partial justification of the fact that basic theoretical models usually disregard mixed market configurations. At the same time, our present theoretical investigation makes clear that the simple assumption of pure oligopolistic versus monopolistically competitive market structure should be motivated and based on structural features of markets and firms, such as the key parameters scaling marginal and average production cost and product substitutability, in relation with the population of firms.

\section{Concluding remarks}

We have taken into account the possibility for firms of strategically choosing whether or not to consider the effect of their own production decision upon the market allocation. This amounts to saying that firms can choose whether to behave in an oligopolistic or monopolistically competitive way. Our approach has shown that the textbook assumption of oligopolistic markets or monopolistically competitive settings is far from being an innocent and robust assumption, if firms can strategically choose whether or not to consider the effect of their decision on the market aggregate supply, and hence the strategic interdependence links among themselves.

It could appear a little bit strange that a firm can choose to disregard 
relevant information, and specifically the information concerning interdependence links among firms and the effect of its own production level choice on the whole market. However, in different contexts, theoretical and experimental economic literature proves that the value of information can be negative, so that, under some admissible circumstances, it can be convenient for individuals to disregard relevant pieces of information. More importantly, we have shown that a firm can easily resort to meaningful mechanism to commit itself to disregard the interdependence links: for example, a managerial delegation contract, with a specific remuneration structure for managers, can lead an oligopolistic firm to behave as if it disregarded altogether the information concerning the interdependence links, that is, as if it were a monopolistically competitive firm.

We have studied the individual incentive for a profit-seeking firm to consider or not the strategic interdependence link in a market for differentiated goods served by $n \geq 2$ producers. We have focused on the supply side, leaving consumer surplus and welfare aside. We have shown that the unilateral deviation from a situation in which all firms behave as oligopolistic subjects may be individually convenient under certain parameter conditions, and, in particular, if the firms' population is large. Also the unilateral deviation from the fully monopolistically competitive setting is profitable under specific circumstances. More specifically, this happens when the population of firms is small. In case of mixed behaviours within the firms' population, for a given partition of firms between oligopolistic and monopolistically competitive sellers, the monopolistically competitive firms obtain a larger profit than the oligopolistic ones, essentially because the monopolistically competitive firms constraint themselves to larger production levels. However, such a situation can not be a stable partition. Indeed, we have shown that an individual profit incentive to switch to the alternative behaviour is always present. We have also shown that, depending on the parameter constellation, three cases are possible: one where the unique equilibrium is purely oligopolistic; one in which the unique equilibrium is the monopolistically competitive outcome; and the other in which both emerge as pure-strategy equilibria. In this last case, one can not disregard the equilibrium in mixed strategies, which delivers a theoretical foundation to the observation of mixed structures in the real world. Be that as it may, the only Pareto efficient outcome from the standpoint of firms is that where all of them behave as oligopolistic agents.

As a last observation, it is worth stressing that all of the above considerations stem from comparative statics carried out on a static model. A truly 
dynamic approach identifying the elements driving the firms' choices in terms of their degree of awareness about strategic interdependence is in our future research agenda.

\section{References}

[1] Anderson S., N. Erkal and D. Piccinin (2013), "Aggregative oligopoly games with entry", CEPR Discussion paper 9511.

[2] Barros F. (1997) "Asymmetric information as commitment in oligopoly", European Economic Review, 41, 207-25.

[3] Bassan, B. and M. Scarsini (1995), "On the value of information in multi-agent decision theory", Journal of Mathematical Economics, 24, $557-76$.

[4] Bassan, B., M. Scarsini and S. Zamir (1997), "I don't want to know! Can it be rational?", Discussion paper no. 158, Center for Rationality and Interactive Decision Theory, The Hebrew University of Jerusalem.

[5] Bassan, B., O. Gossner, M. Scarsini and S. Zamir (2003), "Positive value of information in games", International Journal of Game Theory, 32, 17-31.

[6] Baye M.R., K. Crocker and J. Ju (1996), "Divisionalization, franchising and disinvesture incentives in oligopoly", American Economic Review, 86, $223-36$.

[7] Bowley, A.L. (1924), The mathematical groundwork of economics, Oxford, Oxford University Press.

[8] Chirco, A., C. Colombo and M. Scrimitore (2013), "Quantity competition, endogenous motives and behavioral heterogeneity", Theory adn Decisions, 74, 55-74.

[9] d'Aspremont, C., A. Jacquemin, J.J. Gabszewicz and J. Weymark (1983), "On the stability of collusive price leadership", Canadian Journal of Economics, 16, 17-25. 
[10] Dixit, A.K. (1979), "A model of duopoly suggesting the theory of entry barriers", Bell Journal of Economics, 10, 20-32.

[11] Donsimoni, M.-P., N.S. Economides and H.M. Polemarchakis (1986), "Stable cartels", International Economic Review, 27, 317-27.

[12] Dunne, T., S. D. Klimek, M. J. Roberts and D. Yi Xu (2013), "Entry, exit, and the determinants of market structure", RAND Journal of Economics, 44, 462-87.

[13] Etro, F. (2008), "Stackelberg Competition with Endogenous Entry", Economic Journal, 118, 1670-97.

[14] Etro, F. (2011), "Endogenous Market Structures and Contract Theory: Delegation, Principal-Agent Contracts, Screening, Franchising and Tying", European Economic Review, 55, 463-79.

[15] Etro, F. (2012) "Endogenous Market Structure and Welfare", Ca' Foscari Univeristy of Venice Working paper 2012/12.

[16] Fershtman, C. and K. Judd (1987), "Equilibrium incentives in oligopoly", American Economic Review, 77, 927-40.

[17] Kadane, J.B., M.J. Shervish and T. Seidenfel (1996), "Reasoning to a forgone conclusion", Journal of the American Statistical Association, 91, 1228-35.

[18] Kamien, M.I., Y. Tauman and S. Zamir (1990), "On the value of information in a strategic conflict", Games and Economic Behavior, 2, 129-53.

[19] Kokovin, S., M. Parenti, J.-F. Thisse and E. Zhelobodko (2014), "Markets with dominant firms and competitive fringes", CORE, mimeo.

[20] Lambertini, L. and M. Trombetta (2002), "Delegation and firms' ability to collude", Journal of Economic Behavior and Organization, 47, 35973 .

[21] Melitz, M. and G.I.P. Ottaviano (2008), "Market size, trade, and productivity", Review of Economic Studies, 75, 295-316. 
[22] Miller, N.H. and A.I. Pazgal (2001), "The equivalence of price and quantity competition with delegation", RAND Journal of Economics, 32, 284-301.

[23] Ottaviano, G.I.P., T. Tabuchi and J.F. Thisse (2002), "Agglomeration and trade revisited", International Economic Review, 43, 409-36.

[24] Parenti, M. (2013), "Large and small firms in a global market: David vs. Goliath", CORE Discussion paper 2013/107

[25] Safra, Z. and Sulganik E. (1993), "The value of information with general preference relations", Working paper 34-93 Tel Aviv University, Faculty of Management.

[26] Shimomura, K.-I. and J.F. Thisse (2012), "Competition among the big and the small", RAND Journal of Economics, 43, 329-47.

[27] Singh, N., and X. Vives (1984), "Price and quantity competition in a differentiated duopoly", RAND Journal of Economics, 15, 546-54.

[28] Sklivas, S. (1987), "The strategic choice of management incentives", RAND Journal of Economics, 18, 452-58.

[29] Spence, A.M. (1976), "Product differentiation and welfare", American Economic Review, 66, 407-14.

[30] Vickers, J. (1985), "Delegation and the theory of the firm", Economic Journal (Conference Supplement), 95, 138-47. 


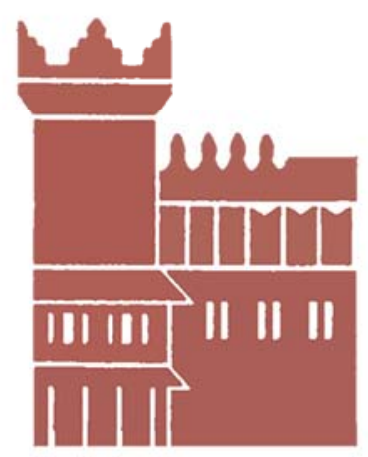

Alma Mater Studiorum - Università di Bologna DEPARTMENT OF ECONOMICS

Strada Maggiore 45

40125 Bologna - Italy

Tel. +39051 2092604

Fax +390512092664

http://www.dse.unibo.it 